\title{
AULAS DE CULINÁRIA PARA CRIANÇAS
}

\section{Crianças descobrem nas artes da cozinha conteúdos de Ciências, Matemática, Português, História e Geografia}

Há muito tempo realizamos com nossos alunos atividades que envolvem o preparo de alimentos. No começo, isto acontecia de forma bastante informal, mas já percebíamos o enorme fascínio das crianças pelo espaço da cozinha, muitas vezes uma área proibida, restrita apenas aos adultos.

Com o tempo estas atividades foram tendo uma importância muito grande no dia-a-dia da escola. O interesse dos alunos foi contagiando a todos. Em 96, tornamos a proposta da culinária parte integrante do nosso currículo, sendo a base do trabalho de Ciências. A curiosidade e o espírito de investigação foram sendo alimentados (literalmente) pelas experiências constantes e contínuas que envolviam o desenvolvimento das primeiras atitudes científicas.

Estes elementos foram enriquecendo o trabalho e nos levando a criar outros caminhos. Foram aparecendo, no desenvolvimento do processo, as demais áreas de conhecimento: a Matemática, através das medidas (de quantidade, de tempo) e jogos de estimativa; a Língua Portuguesa, na leitura e na escrita dos rótulos e receitas; a Geografia e a História, através de receitas típicas e suas origens culturais; a Arte, ao modelar e imaginar novas formas de preparar os alimentos, dando-nos a possibilidade de realizar um trabalho completo e integrado. Além disso, é claro, o imenso prazer pelo resultado na hora da degustação!

"Há mais fenômenos na cozinha do que pode imaginar nossa vã (e deliciosa) gastronomia. Mas não são fruto do acaso nem passe de mágica: na verdade, resultam de importantes e às vezes complexas reações químicas. A cozinha é, portanto, um grande e divertido labo-

\section{A AUTORA}

Theodora M. Mendes de Almeida

Coordenadora Pedagógica da Escola de Educação Infantil Bola de Neve. ratório científico, e conhecê-lo em detalhes pode ser uma viagem fascinante."' 


\section{RELEXÕES SOBRE A ÁREA DE CIÊNCIAS}

Consideramos que a criança até por volta de 11,12 anos pratica ainda uma pré-Ciência, pois ainda não tem as condições intelectuais necessárias para o desenvolvimento do pensamento científico que, por sua vez, necessita do pensamento formal. Portanto, neste período a pesquisa feita diretamente no ambiente em que vive é de fundamental importância. As atividades experimentais devem ser constantes, pois elas propiciam a possibilidade de investigação do real, dão margem à discussão e à interpretação dos resultados obtidos, levando a conclusões.

Ao propor as atividades de culinária queremos evitar uma aprendizagem mecânica de Ciências, na qual predomina uma listagem de nomes a serem memorizados e leis preestabelecidas. Acreditamos que o aluno pode construir seu próprio conhecimento, partindo de situações concretas e elaborando, em seguida, reflexões sobre a prática.

O conhecimento que irá adquirindo gradativamente, através de experimentações e teorizações simples, já fornecerá os pré-requisitos para estudos posteriores cada vez mais complexos, que serão desenvolvidos nas séries seguintes.

Assim, nossos objetivos principais foram:

- Propor atividades que propiciassem a exploração de fatos cotidianos;

- Enfatizar cuidados necessários com higiene e segurança no preparo dos alimentos;

- Estimular a criança a nomear tudo o que está à sua volta;

- Explorar objetos variados levantando suas características de forma, tamanho, espessura, textura, cor, odor, sabor etc.;

- Possibilitar a observação de mudança de estado físico: líquido para sólido, líquido para gasoso etc.; de acordo com a temperatura e a intervenção nos elementos;

- Estimular o levantamento de hipóteses sobre os resultados que seriam obtidos;

- Possibilitar o contato com a leitura de rótulos e das receitas, ampliando o vocabulário e favorecendo o registro através de desenho e escrita;

- Apontar as questões relativas à qualidade da alimentação para o desenvolvimento de uma vida saudável;

- Alertar para as necessidades de reaproveitamento de embalagens e reciclagem do lixo; 
- Transmitir conteúdos socioculturais, como a origem de receitas típicas de lugares específicos.

- Valorizar a socialização através da troca e da união do grupo na hora de preparar e experimentar os alimentos.

\section{CONVERSA SOBRE CULINÁRIA}

Iniciou-se uma conversa sobre culinária com crianças de 6 anos de idade, a partir da observação dos cartazes feitos por elas, nos quais haviam colado diversas figuras de alimentos recortadas de revistas. Elas fizeram também a classificação dos alimentos doces e salgados. A professora perguntou a elas: Se quiséssemos comer todas estas coisas, precisaríamos só estalar os dedos e pronto?

Respostas das crianças:

Cláudia: - Precisa ter um fogão e tomar cuidado.

Edu: - Precisa dos ingredientes.

Vanessa: - Precisa da receita.

Professora: -E se fosse uma musse de maracujá, por exemplo?

Edu: - Não teria problema porque não precisa do fogo para fazê-la.

Professora: - É?! Por que não?

Edu: - Porque não é quente.

Victor: - O sagu é frio e vai no fogo antes.

Arthur: - A gelatina também.

Conversaram sobre alimentos que vão ao fogo e depois à geladeira. Discutiram sobre o assunto e iniciaram uma conversa sobre a importância dos eletrodomésticos e dos utensílios na cozinha.

As crianças exercitaram aqui, através da discussão, a contraposição de idéias e a comunhão de informações. A observação não era suficiente para se chegar às respostas. A experiência de cada um foi sendo acrescentada e levada em consideração para a construção do conhecimento do grupo. Aprofundaram seus conceitos sobre temperatura, mudança de estados físicos, classificação etc.

\section{Roteiro de uma aula de culinária}

Dia anterior ao preparo de uma receita:

Escolha da receita pelos alunos;

Leitura da lista de doces e salgados;

Leitura dos ingredientes;

Divisão dos ingredientes que serão trazidos de casa;

Escrita do bilhete. 
Dia do preparo:

Higiene;

Verificação dos ingredientes através da leitura dos rótulos;

Separação dos utensílios;

Leitura do preparo (ênfase ao vocabulário);

Experimentação dos ingredientes;

Intervenções do professor durante o preparo;

Previsões (levantamento de hipóteses);

Comprovação das hipóteses (ou não);

Informações gerais (alimentos, História, Geografia etc.);

Registro: dependendo da idade, coletivo (em cartazes) ou individual (com símbolos, rótulos, números, desenho e escrita).

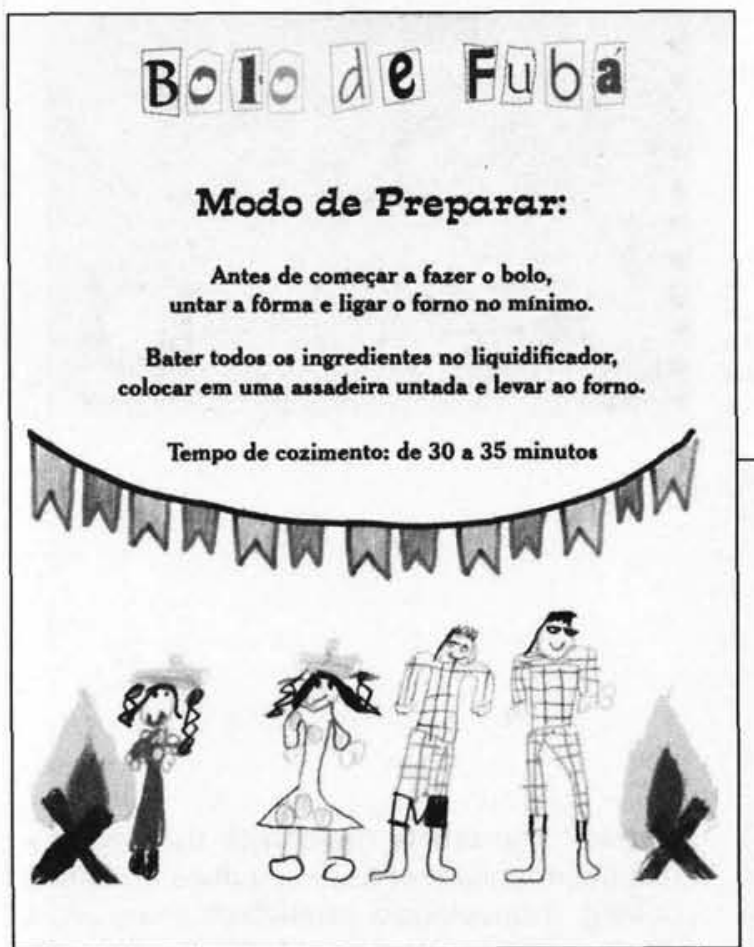

Uma receita de bolo de fubá, ilustrada e preparada por alunos de 1 a 7 anos da escola Bola de Neve.

Bolo de Fubá

\title{
Ingredientes:
}

\author{
$1 \int_{10 \text { inteiros }}^{30}$ de leite de côco \\ 100 gramas de margarina \\ 1 pacote de cóco ralado \\ 2 Ge्य de fubá \\ 1 cas de farinha de trigo
}




\section{LIVRO DE RECEITAS PARA CRIANÇAS: HORA DO LANCHE}

A idéia de fazer um livro surgiu como forma de homenagear os 30 anos do Colégio Bola de Neve. Escolhemos receitas (doces e salgadas), todas elas testadas, experimentadas e aprovadas por nossos alunos com idade entre 1 e 7 anos.

As ilustrações foram escolhidas a partir dos registros feitos em classe pelos alunos.

Em uma grande festa com direito a autógrafos das crianças fizemos o lançamento do livro.

Desta forma, dividimos com todos o sabor e o prazer de um trabalho bem-feito!

Capa do livro de receitas, resultado do trabalho dos alunos das aulas de culinária.

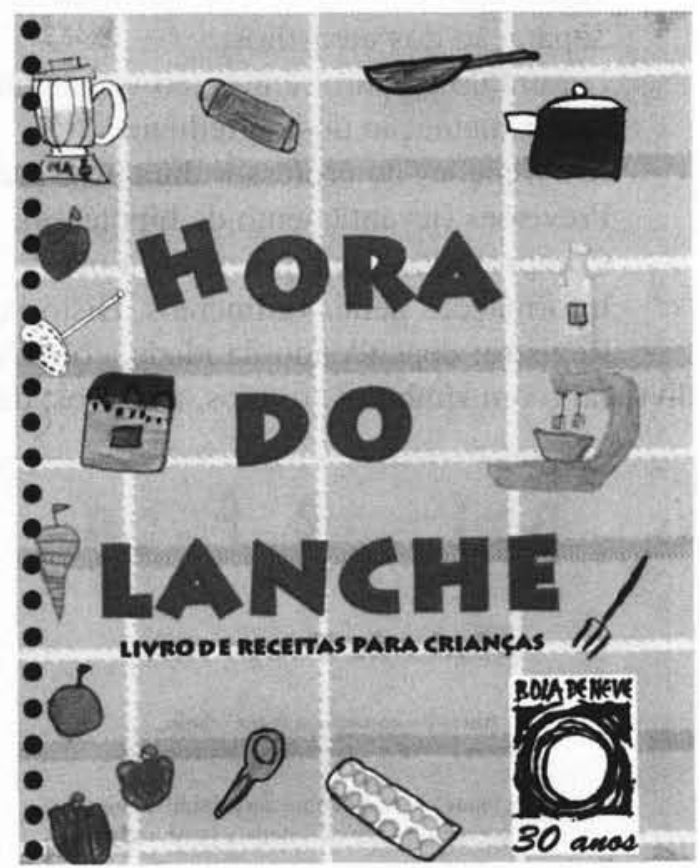

Resumo: $\mathrm{O}$ artigo relata experiência pedagógica que se utiliza das atividades que envolvem o preparo de alimentos. Desenvolve trabalho multidisciplinar no qual, além de Ciências, são tratados conteúdos de Matemática, Português, História e Geografia. As atividades com a culinária permitem unir o grupo, possibilitando que os experimentos e a investigaçāo de possibilidades e hipóteses transcorram de maneira lúdica. $O$ resultado do trabalho deu origem a um livro de receitas, todas testadas e ilustradas por alunos de 1 a 7 anos.

Palavras-chave: culinária, multidisciplinaridade, Ciência, livro de receitas
Abstract: The article deals with the pedagogical experience that uses activities involving cooking. It develops a multidisciplinary work where, besides science, Math, Portuguese, history and Geography are treated. The cooking activities keep the group together, allowing the experiments and the investigation of possibilities and hypothesis to be done in a ludic manner. The result of this work was a recipe book, all tested and ilustrated by 1 to 7 year old students.

Keywords: Cooking, multidisciplinary, Cience, recipe book 